\title{
Períodos de Interferência de Plantas Daninhas na Cultura da Cenoura em Função do EspaÇamento entre Fileiras
}

\author{
Periods of Weed Interference in Carrot in Function of Spacing Between Rows \\ FREITAS, F.C.L. ${ }^{2}$, ALMEIDA, M.E.L. ${ }^{3}$, NEGREIROS, M.Z. ${ }^{4}$, HONORATO, A.R.F. ${ }^{3}$, MESQUITA, H.C. ${ }^{3}$ \\ e SILVA, S.V.O.F. ${ }^{3}$
}

\begin{abstract}
RESUMO - Objetivou-se com este trabalho determinar os periodos de interferência das plantas daninhas na cultura da cenoura (Daucus carota), cultivada em dois espaçamentos. O delineamento experimental foi em blocos ao acaso, no esquema fatorial $2 \times 14$, com quatro repetições. Os tratamentos consistiram na combinação de dois espaçamentos (15 x 6 $\mathrm{cm}$ e $20 \times 6 \mathrm{~cm}$ ) e sete periodos iniciais de controle ou convivência da cultura com as plantas daninhas $(0,12,24,36,48,60$ e 72 dias após a emergência). Os períodos críticos de prevenção à interferência (PCPI) foram de 19 a 36 e 18 a 42 dias após emergência da cultura, respectivamente para os espaçamentos de $15 \times 6 \mathrm{~cm}$ e $20 \times 6 \mathrm{~cm}$ entre fileiras. O menor espaçamento entre fileiras resultou na redução do período crítico de prevenção à interferência das plantas daninhas em sete dias. A interferência das plantas daninhas durante todo o ciclo reduziu a produtividade de cenoura em até $96 \%$.
\end{abstract}

Palavras-chave: Daucus carota, competição, período crítico de prevenção à interferência.

\begin{abstract}
This work aimed to determine the periods of weed interference in carrot (Daucus carota) cultivated in two spacings $(15 \times 6 \mathrm{~cm}$ and $20 \times 6 \mathrm{~cm})$. The experimental design was arranged in a randomized block in a $2 \times 14$ factorial scheme, with two repetitions. The treatments consisted in the combination of the two spacings and seven initial periods of control or coexistence of the culture with the weeds( 0, 12, 24, 36, 48, 60, and 72 days after emergence). The critical periods of weed interference prevention (CPWIP) were from 19 to 36 and 18 to 42 days after crop emergence, respectively, for spacing rows from $15 \times 6 \mathrm{~cm}$ to $20 \times 6 \mathrm{~cm}$. The shortest spacing between the rows resulted in the reduction of the critical period of weed interference prevention in carrot in seven days. Weed interference throughout the crop cycle reduced crop yield up to $96 \%$.
\end{abstract}

Keywords: Daucus carota, competition, critical period of weed interference prevention.

\section{INTRODUÇÃO}

A cenoura (Daucus carota) caracteriza-se como uma das mais importantes olerícolas, pelo seu consumo mundial, pela extensão de área plantada e pelo desenvolvimento socioeconômico dos produtores rurais. No Brasil encontram-se entre as cinco hortaliças mais cultivadas, com consumo de $4,29 \mathrm{~kg}$ por pessoa ao ano, constituindo-se em uma das principais hortaliças de raiz, quanto ao valor econômico. Cultivada em todo o território nacional, a produção brasileira de cenoura é de 785 mil toneladas (Embrapa, 2008), com destaque para as regiões Sudeste (MG e SP), Sul (PR) e, recentemente, Nordeste (BA).

1 Recebido para publicação em 6.10.2008 e na forma revisada em 21.8.2009.

2 Professor Adjunto do Dep. de Ciências Vegetais, Universidade Federal Rural do Semiárido - UFERSA, 59625-900 Mossoró-RN, $<$ fclaudiof@yahoo.com.br>; ${ }^{3}$ Estudante de graduação do curso de Agronomia - UFERSA; ${ }^{4}$ Professor Associado do Dep. de Ciências Vegetais - UFERSA. 
A competição exercida pelas plantas daninhas constitui um dos fatores que mais limitam a produtividade da cultura da cenoura. A intensidade da competição normalmente é avaliada por meio de decréscimos de produção e/ou pela redução no crescimento da planta cultivada, como respostas à competição pelos recursos de crescimento disponiveis no ambiente - no caso, $\mathrm{CO}_{2}$, água, luz e nutrientes (Agostinetto et al., 2008).

Dos vários fatores que alteram o balanço de interferência entre a cultura e as plantas daninhas, destaca-se o período em que ela e as plantas cultivadas estão competindo com os recursos do ambiente. Pitelli \& Durigan (1984) propuseram os conceitos de período anterior à interferência (PAI), periodo total de prevenção à interferência (PTPI) e período crítico de prevenção à interferência (PCPI). O PAI é conceituado como o período a partir da emergência ou do plantio em que a cultura pode conviver com as plantas daninhas antes que a sua produtividade ou outras características sejam alteradas negativamente. O PTPI é o período, a partir da emergência ou do plantio, em que a cultura deve ser mantida livre da presença das plantas daninhas para que sua produtividade, qualidade da produção ou outras características não sejam alteradas negativamente. Como PCPI entende-se o período em que o controle das plantas daninhas deve ser realizado obrigatoriamente, situando-se entre os limites superiores do PAI e do PTPI.

Estudos realizados com outras culturas anuais demonstram que a duração de cada período (em dias) varia com a cultura e as plantas daninhas presentes na área, podendo ser influenciada também pelas espécies e pela densidade de plantas daninhas e pelas práticas de manejo adotadas. Quanto maior a população da comunidade infestante, maior será a quantidade de indivíduos que disputam os recursos do meio e mais intensa será a competição com a cultura. Além disso, espécies morfológica e fisiologicamente próximas apresentam exigências semelhantes em relação aos recursos, tornando ainda mais intensa a competição (Silva \& Durigan, 2006).

Entre as práticas de manejo, a redução do espaçamento entre fileiras pode influenciar positivamente o controle de plantas daninhas. Diversas pesquisas estão evidenciando que espaçamentos menores propiciam menor interferência das plantas daninhas nas culturas, como consequência do fechamento mais rápido do dossel vegetativo (Brizuela, 1994; Teasdale, 1995; Braz, 1996; Dias et al., 2009). Essa cobertura mais rápida do solo pela cultura pode reduzir as doses dos herbicidas e/ou o número de capinas para o controle das plantas daninhas.

Objetivou-se neste trabalho determinar o Período Anterior à Interferência (PAI), o Período Total de Prevenção à Interferência (PTPI) e o Período Crítico de Prevenção à Interferência (PCPI) das plantas daninhas na cultura da cenoura em função da variação do espaçamento entre fileiras.

\section{MATERIAL E MÉTODOS}

O trabalho foi realizado entre os meses de agosto e outubro de 2007, no setor de Fitotecnia da UFERSA, em Mossoró-RN, situado a $5^{\circ} 11^{\text {' }}$ de latitude S e $37^{\circ} 20^{\prime}$ de longitude WGr e com altitude de $18 \mathrm{~m}$, num Argissolo VermelhoAmarelo eutrófico, cuja análise química revelou os seguintes resultados: $\mathrm{pH}$ (água) $=7,9$; $\mathrm{P}=157 \mathrm{mg} \mathrm{dm}^{-3} ; \mathrm{K}=0,3 \mathrm{cmol}_{\mathrm{c}} \mathrm{dm}^{-3} ; \mathrm{Ca}=$ $3,2 \mathrm{cmol}_{\mathrm{c}} \mathrm{dm}^{-3} ; \mathrm{Na}=0,32 \mathrm{cmol}_{\mathrm{c}} \mathrm{dm}^{-3} ; \mathrm{e} \mathrm{Mg}=$ $1,0 \mathrm{cmol}_{\mathrm{c}} \mathrm{dm}^{-3}$. O clima da região, segundo a classificação de Köppen, é BSwh, seco e muito quente, com duas estações climáticas: uma seca, de junho a janeiro, e outra chuvosa, de fevereiro a maio (Carmo Filho et al., 1991).

O experimento foi delineado em blocos ao acaso, em esquema fatorial $2 \times 14$, com quatro repetições. Os tratamentos consistiram na combinação de dois espaçamentos $(15 \times 6 \mathrm{~cm}$ e $20 \times 6 \mathrm{~cm}$ ) e sete períodos iniciais de controle e convivência da cultura com as plantas daninhas. No primeiro grupo de tratamentos, a cultura permaneceu livre da competição com as plantas daninhas, por meio de capinas, por sete períodos, a partir da emergência: 0 dia (testemunha sem capinas), 0-12 dias, 0-24 dias, 0-36 dias, 0-48 dias, 0-60 dias e 0-72 dias (colheita - testemunha mantida no limpo). Após cada uma dessas épocas, as plantas daninhas que emergiram foram deixadas crescer livremente. No segundo grupo, a cultura conviveu com as plantas daninhas por sete periodos a partir da emergência desta: 0 dia (testemunha mantida no limpo), 0-12 dias, 0-24 dias, 0-36 dias, 0-48 dias, 
0-60 dias e 0-72 dias (colheita - testemunha sem capina), a partir dos quais a cultura foi mantida livre da competição das plantas daninhas, por meio de capinas.

As parcelas foram constituídas por seis fileiras de plantas com 1,20 m de comprimento, dispostas no sentido transversal ao canteiro. A área útil para avaliação constituiu das duas linhas centrais, desprezando-se $20 \mathrm{~cm}$ de cada extremidade das fileiras.

Com base nos resultados obtidos na análise de solo, utilizaram-se $80 \mathrm{t} \mathrm{ha}^{-1}$ de esterco de bovino, $40 \mathrm{~kg} \mathrm{ha} \mathrm{k}^{-1}$ de nitrogênio, $90 \mathrm{~kg} \mathrm{ha}^{-1} \mathrm{de}$ $\mathrm{P}_{2} \mathrm{O}_{5}$ e $30 \mathrm{~kg} \mathrm{ha}^{-1}$ de $\mathrm{K}_{2} \mathrm{O}$, na forma de ureia, superfosfato simples e cloreto de potássio, incorporados no solo por ocasião da confecção dos canteiros.

Aos 30 e 45 DAE foram efetuadas adubações em cobertura, empregando-se $20 \mathrm{~kg} \mathrm{ha}^{-1}$ de nitrogênio na forma de ureia.

O cultivar de cenoura Brasília foi semeado em julho de 2007, diretamente nos canteiros, colocando-se em torno de cinco sementes por "cova". Foi realizado um único desbaste, aos 29 dias após a emergência (DAE), deixando-se apenas uma planta a cada $6 \mathrm{~cm}$ nas fileiras de plantio. Foram efetuadas irrigações pelo sistema de microaspersão, de acordo com a necessidade da cultura.

No final de cada período de convivência e por ocasião da colheita, para os tratamentos com periodos iniciais de controle das plantas daninhas, foram realizadas avaliações de densidade e massa seca dessas plantas, por meio de uma amostragem em quadrado $(30 \times 30 \mathrm{~cm})$, na área útil de cada parcela. As plantas daninhas foram coletadas e separadas por espécie, para determinação do número de indivíduos e da massa seca da parte aérea, obtida por meio de secagem em estufa com circulação forçada de ar a $65^{\circ} \mathrm{C}$, até atingir massa constante. Com base na densidade e massa seca verificada para cada espécie de planta daninha em relação ao total obtido para as espécies avaliadas, foram obtidos os índices de ocorrência e de massa seca por espécie, em porcentagem.

Para a cultura da cenoura, aos 72 DAE (ocasião da colheita), foram coletadas, aleatoriamente, 10 plantas na área útil das parcelas para determinação da produtividade de raízes ( $t \mathrm{ha}^{-1}$ ), a qual foi obtida através da massa média das respectivas raízes, extrapolando-se a produção para área de um hectare, levandose em conta a área ocupada por planta, que foi de 0,009 e $0,012 \mathrm{~m}^{2}$, respectivamente para os espaçamentos entre plantas de $156 \mathrm{~cm}$ e $20 \mathrm{x}$ $6 \mathrm{~cm}$.

Os dados foram submetidos à análise de variância pelo teste $\mathrm{F}$ a $5 \%$ e de regressão pelo modelo sigmoidal de Boltzmann, conforme utilizado por Kuva et al. (2000):

$$
y=\frac{(\mathrm{P} 1-\mathrm{P} 2)}{1+e^{\left(x-x_{0}\right) / d x}}+\mathrm{P} 2
$$

em que: $y=$ produtividade da cenoura em função dos períodos de controle ou convivência; $x=$ limite superior do periodo de controle ou convivência (dias); $\mathrm{P} 1=$ produtividade máxima obtida no tratamento mantido no limpo durante todo o ciclo; $\mathrm{P} 2=$ produtividade mínima obtida no tratamento mantido em convivência com as plantas daninhas durante todo o ciclo; $x_{0}=$ limite superior do período de controle ou convivência, que corresponde ao valor intermediário entre a produtividade máxima e a minima; e $d x=$ velocidade de perda ou ganho de produtividade (tangente no ponto $x_{0}$ ).

Os limites dos períodos de interferência (PAI, PTPI e PCPI) foram determinados tolerando-se perdas máximas de rendimento de raízes para o nível arbitrário de $5 \%$ em relação ao tratamento mantido no limpo durante todo o ciclo, dentro de cada espaçamento entre fileiras.

\section{RESULTADOS E DISCUSSÃO}

A comunidade infestante foi composta por 24 espécies, entre dicotiledôneas e monocotiledôneas, distribuídas em 15 famílias. As espécies que se destacaram com relação a densidade e acúmulo de massa seca foram: trapoeraba (Commelina benghalensis), bredo (Talinum paniculatum), caruru-de-espinho (Amaranthus spinosus), capim-milhã (Digitaria sanguinalis) e quebra-pedra (Phyllanthus tenellus) (Tabela 1).

O número de plantas daninhas por unidade de área foi crescente até 21 e $24 \mathrm{DAE}$ (dias após a emergência) para os espaçamentos 
entre fileiras de 20 e $15 \mathrm{~cm}$, respectivamente, com 1.194 e 1.164 indivíduos $\mathrm{m}^{-2}$, seguido por decréscimo considerável até os $72 \mathrm{DAE}$, ocasião da colheita (Figura 1A). Já o acúmulo de massa seca total das plantas daninhas foi crescente até por volta dos $60 \mathrm{DAE}$, com $1.150,43 \mathrm{~g} \mathrm{~m}^{-2}$, e posterior tendência à estabilização (Figura 1B).

A redução do número de plantas e do acúmulo de massa seca, verificada no final do ciclo da cultura, se deve à predominância de plantas anuais com ciclo curto, que entraram em senescência no final do período experimental, e, principalmente, à competição exercida pelas espécies dominantes, com alta taxa de crescimento inicial e com maior estatura, como $A$. spinosus, que, mesmo com $11,30 \%$ da densidade total, foi responsável por mais de $55 \%$ da massa seca total das plantas daninhas (Tabela 1), que, juntamente com a cultura da cenoura, ocuparam a área, suprimindo as espécies menos competitivas e de porte mais baixo, como $P$. tenellus, que, com $16,8 \%$ da densidade total, foi responsável por apenas $1,15 \%$ da massa seca produzida pelas plantas daninhas. Segundo Brighenti et al. (2004), o acúmulo total de massa seca pode ser considerado indicador mais confiável do que a população de plantas daninhas, no tocante ao grau de competição imposto à cultura.

De acordo com Radosevich et al. (1996), à medida que aumentam a densidade e o desenvolvimento das plantas daninhas, especialmente daquelas que germinaram e emergiram no início do ciclo de uma cultura, intensifica-se a competição interespecífica e a intraespecífica também, de modo que as plantas daninhas mais altas e desenvolvidas

Tabela 1 - Espécies de plantas daninhas e seus índices de ocorrência e de massa seca, em relação à densidade total e massa seca total, respectivamente. Mossoró-RN, 2007

\begin{tabular}{|c|c|c|c|c|}
\hline Nome botânico & Nome comum & Família & $\begin{array}{l}\text { Índice de } \\
\text { ocorrência } \\
\quad(\%)\end{array}$ & $\begin{array}{c}\text { Massa seca } \\
(\%)\end{array}$ \\
\hline Amaranthus spinosus & Caruru-de-espinho & Amaranthaceae & 11,31 & 55,71 \\
\hline Commelina benghalensis & Trapoeraba & Commelinaceae & 21,79 & 18,82 \\
\hline Talinum paniculatum & Bredo & Portulacaceae & 19,69 & 8,11 \\
\hline Alternanthera tenella & Apaga-fogo & Amaranthaceae & 1,30 & 3,77 \\
\hline Eleusiene indica & Capim-pé-de-galinha & Poaceae & 6,38 & 3,29 \\
\hline Digitaria sa nguinalis & Capim-milhã & Poaceae & 6,51 & 2,81 \\
\hline Merremia aegyptia & Jitirana & Convolvulaceae & 0,28 & 1,31 \\
\hline Dactyloctenium aegyptium & Capim-mão-de-sapo & Poaceae & 2,80 & 1,29 \\
\hline Phyllanthus tenellus & Quebra-pedra & Phyllant haceae & 16,80 & 1,15 \\
\hline Portulaca oleracea & Beldroega & Portulacaceae & 2,57 & 1,12 \\
\hline Malva sylvestris & Malva & Malvaceae & 0,35 & 1,02 \\
\hline Croton lobatus & Café-bravo & Euphorbiaceae & 1,58 & 0,91 \\
\hline Cleome affinis & Mussambé & Capparidaceae & 1,29 & 0,71 \\
\hline Turnera ulmifolia & Xanana & Turneraceae & 0,07 & 0,49 \\
\hline Brachiaria decumbens & Capim-braquiária & Poaceae & 0,60 & 0,44 \\
\hline Cyperus rotundus & Tiririca & Cyperaceae & 0,69 & 0,22 \\
\hline Cenchrus echinatus & Carrapicho & Poaceae & 1,31 & 0,18 \\
\hline Hyptis suaveolens & Cheirosa & Labiatae & 0,09 & 0,13 \\
\hline Cucumis anguria & Maxixe & Cucurbitaceae & 0,03 & 0,043 \\
\hline Cynodon dactylon & Grama-seda & Poaceae & 0,13 & 0,03 \\
\hline Crotalaria juncea & Crotalária & Leguminoseae & 4,20 & 0,02 \\
\hline Chamaesyce hyssopifolia & Erva-de-santa-luzia & Euphorbiaceae & 0,86 & 0,008 \\
\hline Eragrotis pilosa & Capim-fino & Poaceae & 0,09 & 0,004 \\
\hline Senna obtusifolia & Fedegoso & Fabaceae-Caesalpinioideae & 0,89 & 0,0003 \\
\hline
\end{tabular}



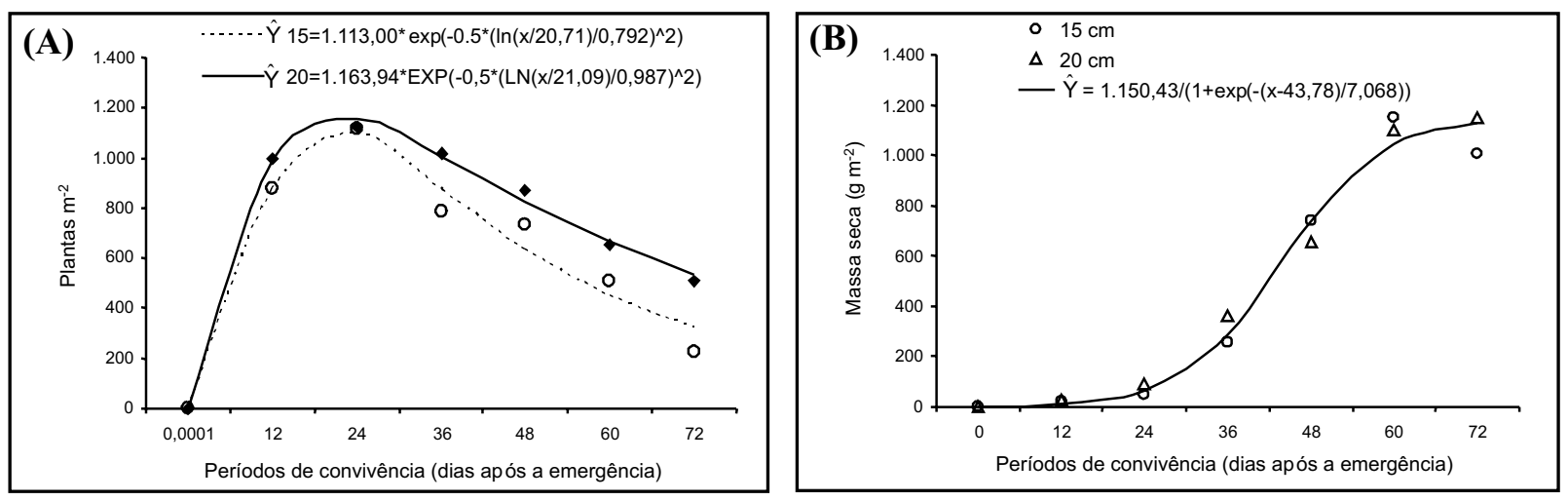

Figura 1 - Densidade (A) e massa seca (B) do total das plantas daninhas que compuseram a comunidade infestante em diferentes períodos de convivência com a cultura da cenoura, para os espaçamentos de 15 e $20 \mathrm{~cm}$ entre fileiras. Mossoró-RN

tornam-se dominantes, ao passo que as plantas menores são suprimidas ou morrem. Esse comportamento explica a redução da densidade das plantas daninhas a partir dos 24 DAE e o aumento da massa seca até os 60 DAE (Figura 1A, B).

Além dos efeitos da competição inter e intraespecífica, a redução na densidade de plantas se deve, também, ao ciclo curto em algumas espécies de plantas daninhas, que é um mecanismo de sobrevivência ao reduzido período de condições ambientais favoráveis, como ocorre no semiárido, com concentração de chuvas em um curto espaço de tempo (Freitas et al., 2009). Diante disso, as plantas necessitam completar seu ciclo rapidamente para não comprometer a perpetuação da espécie.

No tocante aos espaçamentos, fileiras de cenoura mais próximas, espaçadas de $15 \mathrm{~cm}$, resultaram em menor densidade de plantas daninhas na fase final do período experimental, provavelmente como consequência da maior competição exercida pela cultura, que promoveu fechamento do dossel mais cedo que nos tratamentos com fileiras espaçadas de $20 \mathrm{~cm}$ (Figura 1A). Por outro lado, o acúmulo de massa seca de plantas daninhas não foi influenciado pelos espaçamentos das fileiras da cultura (Figura 1B). Isso ocorreu, provavelmente, como consequência da dominância de A. spinosus (Tabela 1), que apresenta taxa de crescimento inicial superior à das demais espécies, inclusive da cultura, que, com plantas mais altas, não chegou a ser influenciada pela redução do espaçamento entre fileiras.
A produtividade da cultura passou a ser afetada negativamente pela convivência com as plantas daninhas a partir dos 19 e $18 \mathrm{DAE}$, respectivamente para fileiras espaçadas de 15 e $20 \mathrm{~cm}$, correspondendo ao PAI; o controle das plantas daninhas teve de ser realizado até os 36 e $42 \mathrm{DAE}$ quando as fileiras foram espaçadas de 15 e $20 \mathrm{~cm}$, respectivamente, correspondendo ao PTPI (Figura 2).

$O$ período crítico de prevenção à interferência (PCPI), que é intervalo entre o PAI e o PTPI, foi de 19 a 36 DAE para o espaçamento de $15 \times 6 \mathrm{~cm}$ e de 18 a 42 DAE para o de $20 \times 6 \mathrm{~cm}$. Na prática, o PCPI representa o periodo que as capinas - ou efeito residual dos herbicidas - devem abranger, pois as plantas infestantes que emergirem nesse período terão um estádio de desenvolvimento tal que promoverão interferência e reduzirão significativamente a produtividade da cultura (Pitelli, 1985). Portanto, o aumento da densidade de plantas de cenoura por meio da redução do espaçamento entre fileiras de 20 para $15 \mathrm{~cm}$ promoveu maior competição interespecífica por parte da cultura em relação às plantas daninhas, resultando na redução de sete dias no PCPI, o que implica redução nos custos de produção. Na cultura da beterraba, o aumento na densidade de plantas, com a diminuição do espaçamento entre fileiras de 25 para $20 \mathrm{~cm}$, resultou em redução de 11 dias no PCPI (Carvalho \& Guzzo, 2008).

Coelho (2005) verificou PCPI entre 25 e 36 dias após a semeadura para cenoura cultivada em fileiras duplas espaçadas entre $10 \mathrm{e}$ $20 \mathrm{~cm}$, entre pares de fileiras. 


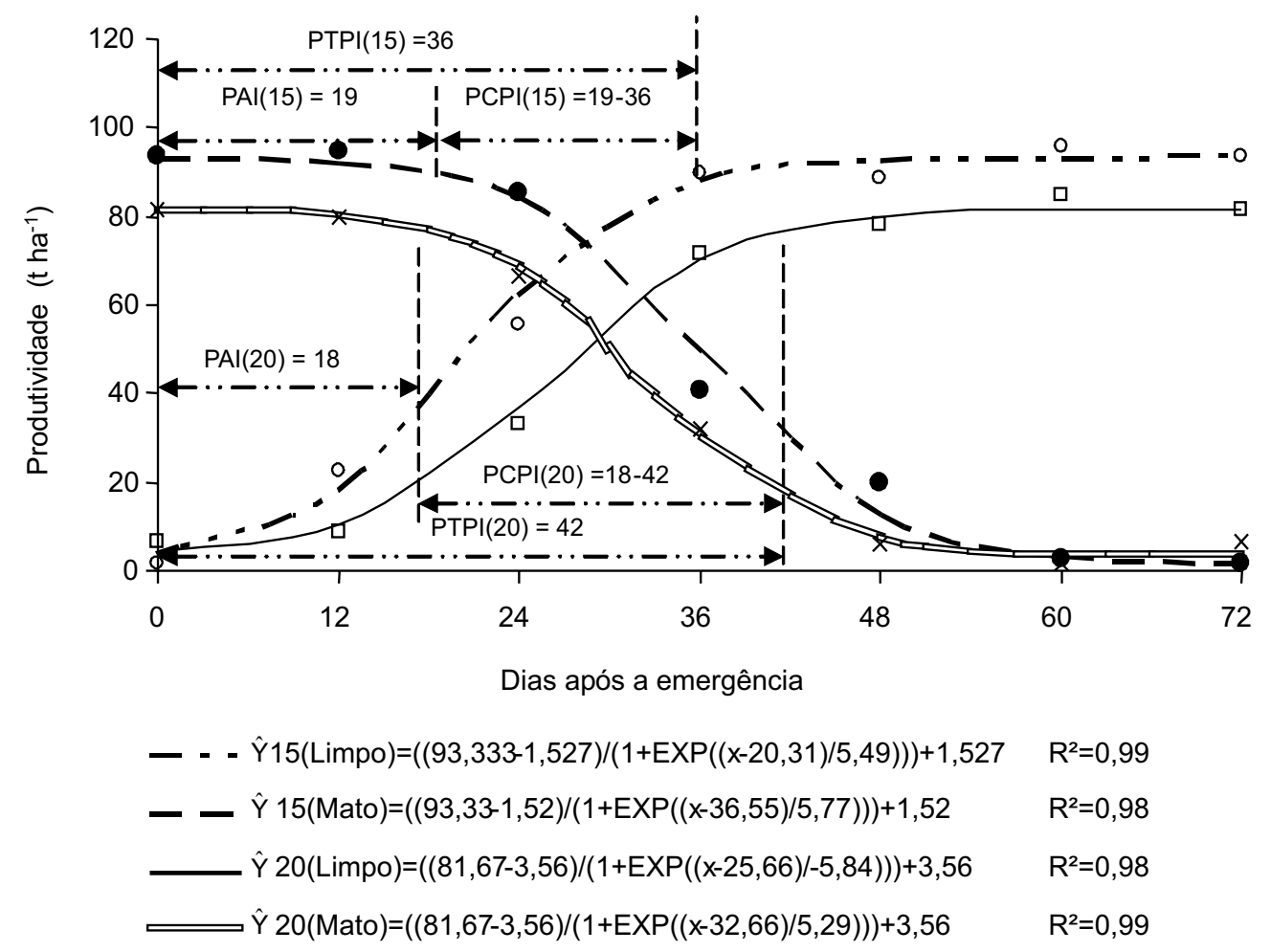

Figura 2 - Produtividade de raízes comercializáveis de cenoura em resposta aos períodos de controle (no limpo) e convivência (no mato) com as plantas daninhas, para os espaçamentos de $15 \times 6 \mathrm{~cm}$ e $20 \times 6 \mathrm{~cm}$, com seus respectivos períodos anteriores à interferência (PAI), períodos totais de prevenção à interferência (PTPI) e períodos críticos de prevenção à interferência (PCPI). Mossoró-RN, 2007.

Verifica-se que o PAI praticamente não foi influenciado pelos espaçamentos entre fileiras (Figura 2), pois nessa época as plantas de cenoura ainda estavam muito pequenas e o aumento na densidade de plantas da cultura não influenciou a interferência exercida pelas plantas daninhas. Entretanto, o PAI mais curto verificado neste trabalho, quando comparado ao obtido por Coelho (2005), deve-se, provavelmente, à grande infestação de plantas daninhas na área e à agressividade de algumas espécies que acumularam grande quantidade de massa seca, especialmente $A$. spinosus (Figura 1A, B). Segundo Meschede et al. (2002, 2004), os fluxos iniciais de germinação das plantas daninhas, que ocorrem logo após a semeadura da cultura, são normalmente os de maior intensidade e densidade e muito importantes em termos da interferência inicial, uma vez que impõem à cultura uma situação de restrição de recursos prematuramente.

Quanto ao PTPI, o espaçamento de $15 \times 6 \mathrm{~cm}$ mostrou redução considerável, de seis dias, em relação ao espaçamento de $20 \times 6 \mathrm{~cm}$, como consequência da maior densidade de plantas, obtida através de fileiras mais próximas, que promoveram fechamento do dossel mais cedo, o que dificulta a emergência e o desenvolvimento das plantas daninhas. Segundo Teasdale (1995) e Silva et al. (2007), a redução no espaçamento ou o aumento na densidade de plantas faz com que a cultura tenha maior capacidade de competição com as plantas daninhas, especialmente por luz, por antecipar o fechamento do dossel, restringindo a passagem desta.

Além da redução do PCPI, a maior densidade de plantas na cultura, no espaçamento de $15 \times 6 \mathrm{~cm}$, resultou também em incremento de $11,67 \mathrm{t} \mathrm{ha}^{-1}$ na produtividade de raízes (Figura 2), demonstrando que a competição interespecífica (cenoura e plantas daninhas) foi mais forte que a intraespecífica (cenoura). Para Silva \& Nepomuceno (1991), a utilização de diferentes densidades de plantas ocasiona competições intraespecíficas de intensidades 
variáveis. Para um mesmo cultivar, a produtividade das culturas geralmente se eleva com o aumento de densidade de plantas até que um ou mais fatores (condições edafoclimáticas ou práticas culturais) se tornem limitantes. Em outras culturas, diversas pesquisas evidenciaram que espaçamentos menores propiciam maiores rendimentos, devido ao aproveitamento mais eficiente da radiação solar, da água e dos nutrientes, além da menor interferência das plantas daninhas, como consequência do fechamento mais rápido do dossel vegetativo (Parvez et al., 1989; Brizuela, 1994; Braz, 1996; Murphy et al., 1996; Casa et al., 2007).

A perda na produtividade de raízes observada nos dois espaçamentos entre fileiras, quando a cultura conviveu por todo o ciclo com as plantas daninhas, foi de 96 e $94 \%$ para os espaçamentos de $15 \times 6 \mathrm{~cm} \mathrm{e}$ $20 \times 6 \mathrm{~cm}$, respectivamente. Esse resultado foi similar ao observado por Blanco \& Oliveira (1971), enquanto Coelho (2005) constatou redução de 60\%. Angeletti (1984) e D'Antonino (1992) verificaram que a infestação de plantas daninhas interferiu no crescimento e desenvolvimento das raízes da cenoura, reduzindo-lhe o tamanho e o diâmetro. Segundo Constantin et al. (2007), mesmo culturas consideradas competitivas podem ser severamente afetadas pela interferência de plantas daninhas, reduzindo o crescimento e a produtividade.

Os períodos críticos de prevenção à interferência (PCPI) foram de 19 a 36 e 18 a 42 dias após emergência da cultura para os espaçamentos de $15 \times 6 \mathrm{~cm}$ e $20 \times 6 \mathrm{~cm}$, respectivamente, resultando em redução de sete dias no PCPI quando se utiliza o menor espaçamento. A convivência da cultura com as plantas daninhas durante todo o ciclo resultou na redução da produtividade de raízes comerciais de cenoura em até $96 \%$.

\section{LITERATURA CITADA}

AGOSTINETTO, D. et al. Período crítico de competição de plantas daninhas com a cultura do trigo. Planta Daninha, v. 26, n. 2 , p. $271-278,2008$

ANGELETTI, M. P. Influência de sistemas de manejo do solo na cultura da cenoura (Daucus carota L.) na serra de Baturite, Ceará. 1984. 44 f. Dissertação (Mestrado em Agronomia) - Universidade Federal do Ceará, Fortaleza, 1984.
BLANCO H. G.; OLIVEIRA, D. A. Duração do período de competição das plantas daninhas com a cultura da cenoura (Daucus carota L.). O Biológico, v. 37, n. 1, p. 3-7, 1971.

BRAZ, B. A. Efeitos de reduções de distâncias entrelinhas e de dosagens de latifolicidas no controle de plantas daninhas na cultura da soja (Glycine max (L.) Merrill). 1996. 143 f. Tese (Doutorado em Produção Vegetal) - Universidade Estadual Paulista, Jaboticabal, 1996.

BRIGHENTI, A. M. et al. Períodos de interferência de plantas daninhas na cultura do girassol. Planta Daninha, v. 22 , n. 2 , p. $251-257,2004$

BRIZUELA, S. F. B. Efeito de variedades, espaçamentos e doses de herbicidas nas relações de interferência entre a cultura da soja e a comunidade infestante. 1994. $112 \mathrm{f}$ Dissertação (Mestrado em Agronomia) - Universidade Estadual Paulista, Jaboticabal, 1994

CARMO FILHO, F. et al. Dados climatológicos de Mossoró: um município semi-árido nordestino. Mossoró: UFERSA, 1991. 121 p. (Coleção Mossoroense, 30).

CARVALHO, L. B., GUZZO, C. D. Adensamento da beterraba no manejo de plantas daninhas. Planta Daninha, v. 26, n. 1, p. $73-82,2008$.

CASA, R. T. et al. Incidência de podridões do colmo, grãos ardidos e rendimento de grãos em híbridos de milho submetidos ao aumento na densidade de plantas. Summa Phytopathol., v. 33, n. 4, p. 353-357, 2007.

COELHO, M. Efeito de diferentes períodos de convivência com as plantas daninhas sobre a produtividade da cultura da cenoura (Daucus carota L.), 2005. 57 f. Dissertação (Mestrado em Agronomia) Universidade Estadual Paulista, Faculdade de Ciências Agrárias e Veterinárias, Jaboticabal, 2005

CONSTANTIN, J. et al. Interação entre sistemas de manejo e de controle de plantas daninhas em pós-emergência afetando o desenvolvimento e a produtividade do milho.

Planta Daninha, v. 25, n. 3, p. 513-520, 2007.

DIAS, T. C. S. et al. Efeito do espaçamento entre fileiras de amendoim rateiro na interferência de plantas daninhas na cultura. Planta Daninha, v. 27, n. 2, p. 221-228, 2009.

D'ANTONINO, L. Efeito de densidades e semeadura e do desbaste no crescimento e na produção da cenoura (Daucus carota L.) cv. 1992. 94 f. Dissertação (Mestrado em Fitotecnia) - Universidade Federal de Viçosa, Viçosa, MG, 1992.

EMPRESA BRASILEIRA DE PESQUISA AGROPECUÁRIA - EMBRAPA. Embrapa Hortaliças. Produção de hortaliças no Brasil, 1980-2004. Disponível em: <http://www.cnph.embrapa.br/paginas/hortaliças em números/planilhas-2004/produção do brasil-2004.htm> Acesso em: 13 mar. 2008.

Planta Daninha, Viçosa-MG, v. 27, n. 3, p. 473-480, 2009 
FREITAS, F. C. L. et al. Interferência de plantas daninhas na cultura do feijão-caupi. Planta Daninha, v. 27, n. 2 , p. 241-247, 2009

KUVA, M. A. et al. Períodos de interferência das plantas daninhas na cultura da cana-de-açúcar. I - Tiririca. Planta Daninha, v. 18, n. 2, p. 241-251, 2000.

MESCHEDE, D. K. et al. Período crítico de interferência de Euphorbia heterophylla na cultura da soja, sob baixa densidade de semeadura. Planta Daninha, v. 20, n. 3, p. $381-387,2002$

MESCHEDE, D. K. et al. Período crítico de interferência em soja: estudo de caso com baixa densidade de estande e testemunhas duplas. Planta Daninha, v. 22, n. 2, p. $239-246,2004$.

MURPHY, S. D. et al. Effect of planting patterns on intrarow cultivation and competition between corn and late emerging weeds. Weed Sci., v. 44, n. 6, p. 856-870, 1996.

PARVEZ, A. Q.; GARDNER, F. P.; BOOTE, K. J. Determinate and indeterminate type soybean cultivar responses to pattern, density, and planting date. Crop Sci., v. 29, n. 1, p. $150-157,1989$.

PITELLI, R. A. Interferência de plantas daninhas em culturas agrícolas. Inf. Agropec., v. 11, n. 1, p. 16-27, 1985 .
PITELLI, R. A.; DURIGAN, J. C. Terminologia para períodos de controle e de convivência das plantas daninhas em culturas anuais e bianuais. In: CONGRESSO BRASILEIRO DE HERBICIDAS E PLANTAS DANINHAS, 15., 1984, Belo Horizonte. Resumos... Belo Horizonte: SBHDE, 1984. p. 37.

RADOSEVICH, S.; HOLT, J.; GHERSA, C. Physiological aspects of competition. In: Weed ecology implications for manegements. New York: John Willey \& Sons, 1996. p. $217-301$

SILVA. A. A. et al. Biologia de plantas daninhas. In: SILVA, A. A.; SILVA, J. F. Tópicos em manejo de plantas daninhas. Viçosa, MG: Universidade Federal de Viçosa, 2007. p. $17-61$.

SILVA, M. R. M.; DURIGAN, J. C. Períodos de interferência das plantas daninhas na cultura do arroz de terras altas. I - Cultivar IAC 202. Planta Daninha, v. 24, n. 4, p. 685-694, 2006

SILVA, P. R. F.; NEPOMUCENO, A. L. Efeito do arranjo de plantas no rendimento de grãos, componentes do rendimento, teor de óleo e no controle de plantas daninhas na cultura do girassol. Pesq. Agropec. Bras., v. 26, n. 9, p. 1503-1508, 1991.

TEASDALE, J. R. Influence of narrow row/high population corn on weed control and light transmittance. Weed Technol., v. 9, n. 1, p. 113-118, 1995. 